\title{
Awareness about Early Detection Methods, Symptoms and Risk Factors towards Breast and Cervical Cancer among the Female Students of Mawlana Bhashani Science and Technology University (MBSTU), Santosh, Tangail, Bangladesh
}

\author{
Fatama Tous Zohora*, Nibedita Paul, Shahin Mahmud, S. M. Neaz Mahmud, Abu Zaffar Shibly \\ Department of Biotechnology and Genetic Engineering, Mawlana Bhashani Science and Technology University, \\ Santosh, Bangladesh \\ Email: ^ftzohora.bge@gmail.com
}

How to cite this paper: Zohora, F.T., Paul, N., Mahmud, S., Mahmud, S.M.N. and Shibly, A.Z. (2017) Awareness about Early Detection Methods, Symptoms and Risk Factors towards Breast and Cervical Cancer among the Female Students of Mawlana Bhashani Science and Technology University (MBSTU), Santosh, Tangail, Bangladesh. Advances in Breast Cancer Research, 6, 49-67.

https://doi.org/10.4236/abcr.2017.62005

Received: January 9, 2017

Accepted: April 2, 2017

Published: April 5, 2017

Copyright ( 92017 by authors and Scientific Research Publishing Inc. This work is licensed under the Creative Commons Attribution International License (CC BY 4.0).

http://creativecommons.org/licenses/by/4.0/ (c) (i) Open Access

\section{Abstract}

The study was conducted to ensure knowledge, attitude, awareness about breast and cervical cancer among the female students of Mawlana Bhashani Science and Technology University. This study was carried out from July to September, 2015 among the participants of university female halls, different female hostels and different faculty of the university by using a validated questionnaire which was developed for this study. A total 250 female students, at the age of (18 - 26) years were participated. Collected information was analyzed using SPSS, Graph-pad Prism and MS Excel. The results showed that about $87.6 \%$ participants were undergraduate. Most of them come from village (45.6\%) and city (36.0\%). About $90 \%$ were Muslims and the socioeconomic level of most of the participants was middle (90.4\%). In case of food intake patterns, it was observed that $35.6 \%$ participants eat chips, soft drinks, popcorn everyday; $40.4 \%$ eat meat regularly; $24 \%$ eat sugar everyday; $27.6 \%$ eat fruits and vegetables every day. Among them, 55.6\% girls maintained daily 1 hour physical activity; $37.2 \%$ did exercise rarely; $34.8 \%$ participants rarely do strenuous exercise. About $84.4 \%$ respondents have not any family history of cancer; $6 \%$ participants have sister or mother having breast tumor and $7.2 \%$ have at least more than one close relative who have cancer. Among the participants, only $0.8 \%$ drank alcohol; $1.2 \%$ have addiction of smoking cigarette; $15.6 \%$ girls wear tight bra; $3.6 \%$ have benign breast disease and $2.8 \%$ participants have attended in breast or cervical cancer screening programs. The 
moderate numbers of girls have breast cancer screening practice. Among them, only $28.8 \%$ participants have ever heard about BSE (Breast self-examination) and $40.4 \%$ have not any knowledge about breast cancer treatment. About $50.8 \%$ respondents don't have any knowledge about cervical cancer treatment. The village people are the most risky group. About $17.02 \%$ girls recognized weakened immune system as a risk factor of cervical cancer. It can be concluded that, knowledge of participants regarding breast and cervical cancer is poor. Targeted education should be implemented to improve the knowledge of respondents about early detection methods and symptoms of breast and cervical cancer.

\section{Keywords}

Breast Cancer, Cervical Cancer, Risk Factors, Symptoms, Awareness, Treatments

\section{Introduction}

Cancer is one of the major causes of morbidity and mortality among non communicable diseases in Bangladesh and all over the world [1]. According to the Bangladesh Bureau of Statistics, cancer is the sixth leading cause of death in Bangladesh. International Agency for Research on Cancer has estimated that cancer-related death rate in Bangladesh was 7.5\% in 2005 and it will reach 13\% in 2030 [2]. It has predicted that cancer will be the first and main cause of morbidity and mortality in Bangladesh in the next few decades. It was estimated that about 12.7 million new cancer cases will be raised to 21.4 million by 2030. The two leading causes of death in males are lung and oral cancer and in females are breast and cervical cancer [3].

Breast cancer (BC) in women is a major public health problem worldwide [4]. Breast cancer is a leading cause of cancer-related death in women. This disease is diagnosed in nearly 1.4 million women and is responsible for more than 450,000 deaths every year [5]. According to the WHO, there has been about $20 \%$ increase in the number of reported breast cancer patients worldwide which resulted in 522,000 deaths since 2008. According to the US National Cancer Institute, breast cancer is responsible for about 4000 deaths in the USA each year. Breast cancer is not gender specific [6] [7]. The frequency of breast cancer in men is approximately 100-fold lower than in women [8]. In another study, it was estimated that there are approximately 2.5 million survivors of breast cancer that are present in the USA [9]. This number will expand to 3.4 million in 2015, indicating an increase of $31 \%$ [10]. Millions more people worldwide are probably grossly underestimated because of the poor or inefficient reporting systems and the lack of reliable cancer registries in third-world countries [11] [12]. Substantial advances have been made in the treatment of breast cancer, but the affordance to introduce of these methods to predict cancer at elevated risk level and to prevent this disease is still less successful [13]. Large population-based registry 
studies have shown that breast cancer prognosis is inherited. It can be considered single-nucleotide polymorphisms (SNPs) of genes implicated in human-immunology and inflammation as candidates for prognostic markers of breast cancer survival [14]. Most breast cancers are diagnosed by determining estrogen receptor (ER)-positive and cells depend on estrogen for growth and survival. Blocking estrogen biosynthesis by aromatase inhibitors (AI) has therefore become a first-line endocrine therapy for post-menopausal women with ER-positive breast cancers [15]. It is critical to establish a relationship between the different mammographic density phenotypes (absolute dense area, absolute non-dense area, and percentage dense area) and breast cancer risk to uncover underlying biological mechanisms and to improve upon breast cancer risk prediction modeling [16]. The ability to characterize entire genomes at base pair level using massively parallel sequencing technologies provides a unique opportunity to unravel genotypic-phenotypic associations in breast cancer, which can be exploited for the identification of drivers of tumourigenesis [17]. Invasive lobular breast cancer (ILC) is accounts for $10 \%-15 \%$ of all invasive breast carcinomas and it has distinct etiological, clinical and biological characteristics compared with the more common invasive ductal type carcinoma (IDC) [18]. In Iran, breast cancer is ranked first among malignancies in women [19]. So it is very important to raise awareness among young women. The earlier the breast cancer is detected, the better the effectiveness of the treatment. Breast cancer screening includes breast self-examination, clinical breast examination, mammography etc., and these are usually done in combination [20]. Breast self-examination (BSE) is a widely used screening method to detect early breast cancer which involves the woman herself looking at and feeling each breast for possible lumps, distortions or swelling. BSE is a simple, inexpensive, non-invasive procedure which helps a woman to know about her breast and allows her to detect changes in the breast; such as breast masses or lumps [21].

Cervical cancer is one the most common cancer in women world-wide with a significant rate of mortality, particularly in developing countries [22]. Cervical cancer incidence and mortality rates have dropped dramatically during the 20th century in developed countries due to implementation of screening programs [23]. Cervical cancer is one of the most frequent diseases in the world, and the second type of cancer that kills most women worldwide, with an estimated global incidence of 470,000 in new cases and over 200,000 deaths in per year [24] [25]. One of the first events in cervical cancer development is the infection with human papilloma virus (HPV). HPV is associated with benign and malignant cervical lesions in infecting mucosa and epithelial surfaces of the cervix. HPV replication occurs exclusively in squamous stratified epithelium (such as the epidermis and mucous membranes) [26] which is depend on the cellular differentiation state and abundance of important proteins like transcriptional factors, polymerases, splicing factors, RNA processing machinery etc. [27]. In another study, it was also shown that cervical cancer is one of the major causes of death in women with about 454,000 new cases and 200,000 deaths in 2010 worldwide [28] [29]. Human papillomavirus (HPV) infection is the most important risk 
factor for cervical cancer [30]. As the awareness of the cancer among women has been grown gradually, so cancer screening services have become widely accepted as an important part of well women's health care services [31]. With proper screening and early intervention, cervical cancer, caused by infection with particular types of human Papilloma virus (HPV), is a highly treatable disease. As it is generally needed a long time period for cancer development, so it is also generally preventable [32]. Several challenges face cervical cancer screening programs and help-seeking for cervical cancer in South Asia [33]. Despite the declining incidence of cervical cancer as a result of the introduction of screening programs, globally still now it remains a leading cause of cancer-related death in women [34]. Moreover, the age distribution of cervical cancer is changing and many studies regarding appropriate commencing age of screening are being reported [35]. Uterine cervical cancer still remains an important socioeconomic issue because it largely affects women of reproductive age [36]. Mortality rates declined rapidly in past decades due to prevention and early detection, as a result of screening with the Pap test. However, similar to incidence, mortality rates have begun to level off in recent years, particularly among younger women. From 2007 to 2011, death rates were stable among women younger than 50, but decreased by $1.1 \%$ per year among those 50 years of age or older [37].

A systematic analysis by IHME published in 2011 found that as the global incidence of breast cancer more than doubled between 1980 and 2010, the share of breast cancer cases in LMICs increased from about a third to just over half (51\%) [38]. For cervical cancer, the increase in cases has been far slower $(20 \%$ over three decades worldwide) and the shift of the burden toward LMICs even more pronounced. New cases in LMICs increased at a 0.8 percent annual rate between 1980 and 2010, even as incidence in high-income countries declined (IHME, 2011) [39].

The aim of the study was to increase the awareness and knowledge about reasons, risk factors, symptoms, early detection/screening methods and treatments of breast and cervical cancer among the female students of MBSTU.

\section{Materials and Methods}

\subsection{Study Design}

The study was conducted from March 2015 to September 2015 among the female students of Mawlana Bhashani Science and Technology University, Santosh, Tangail. A total of 250 female students were participated.

\subsection{Questionnaire Formation}

A self administered questionnaire prepared by the author. The questionnaire was constructed by following previously validated breast and cervical cancer knowledge-based published surveys [40] [41] [42]. Questionnaire's sensitivity, specificity were established using information on breast and cervical cancer from the different published literature review [43] [44] [45]. The questionnaire consisted of three parts: first part of the questionnaire was included with some gen- 
eral questions such as age, weight, living place, study level, religion, socioeconomic level, regular diet and physical exercise related information. Second part of the questionnaire was consisted of some personal questions about the participants and her family. It was included with marital status, family history about breast and cervical cancer, some habits like drinking alcohol, smoking cigarette; question about HIV, HSV, HPV infection etc. Third part of the questionnaire was focusing the knowledge and awareness about breast and cervical cancer screening practices. It was included with sources of information, questions on symptoms, risk factors, screening tests, knowledge of BSE, Pap test, and ideas about treatments.

\subsection{Statistical Analysis}

The survey included closed multiple choice questions. The statistical analyses were performed using SPSS (Statistical Package for the Social Sciences) version 20.0, Graph-pad Prism version-5.0 and MS Excel-2007.

\section{Result}

Total 250 girls were participants in our study from MBSTU and their age range was 18 - 26 years. The socio demographic profile, food intake patterns, physical activity, family history of cancer, different treatment, symptoms, risk factors of breast and cervical cancer were also revealed.

Above data represent the socio-demographic profile of study participants. In our study it was found that more than half of the participants $(61.2 \%)$ were aged between 21 - 23 years. Most of them were inhabitant of village (45.6\%) followed by city $(36.0 \%)$. Among the 250 participants $87.6 \%$ were under-graduate. The $90 \%$ participants were Muslim and the socioeconomic level of most of the participants was middle class (90.4\%) (Table 1 ).

Food intake patterns of the study participants were quite different (Table 2). Most of them preferred vegetables and fish as their daily meal. Some of them totally avoided health hazardous food items and other junk food or food responsible for obesity due to their health awareness.

Among the respondents, $55.6 \%$ girls were maintained daily 1 hour physical exercise to maintain healthy and smooth fitness, a vital factor to reduce the risk of breast and cervical cancer where $43.2 \%$ were not maintained due to their unconsciousness or lack of interest. About $37.2 \%$ participants maintained exercise rarely and $31.6 \%$ never did it (Table 3 ).

Among the 250 participants, very few girls were fully aware about breast cancer (Figure 1). Among the selected eight risk factors, it was found that most of the participants have lack of knowledge about these (Table 4). Participants were asked about four well known screening methods for breast cancer detection. Total $37 \%$ girls have correct knowledge about at least one early detection methods of breast cancer (Figure 2). Most of them (15.6\%) considered ultra-sound is the easiest and most reliable method for screening. None of them were heard about mammography in the past. Practices of screening methods among respondents 


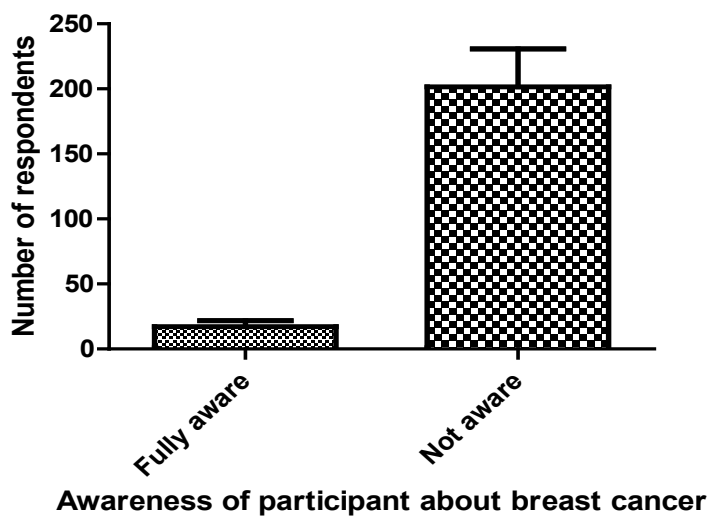

Figure 1. Awareness of participants ( $P$ value $<0.0001$; Remarks-Significant).

Table 1. Socio-demographic profile of study participants.

\begin{tabular}{|c|c|c|}
\hline Age in years & Frequency & Percent (\%) \\
\hline $18-20$ & 66 & 26.4 \\
\hline $21-23$ & 153 & 61.2 \\
\hline $24-26$ & 31 & 12.4 \\
\hline Weight in $\mathrm{kg}$ & Frequency & Percent (\%) \\
\hline $35-50$ & 82 & 32.8 \\
\hline $51-60$ & 134 & 53.6 \\
\hline $61-70$ & 34 & 13.6 \\
\hline Living place & Frequency & Percent (\%) \\
\hline Village & 114 & 45.6 \\
\hline Semi town & 46 & 18.4 \\
\hline City & 90 & 36.0 \\
\hline Study level & Frequency & Percent (\%) \\
\hline Undergraduate & 219 & 87.6 \\
\hline Postgraduate & 31 & 12.4 \\
\hline Religion & Frequency & Percent (\%) \\
\hline Muslim & 225 & 90.0 \\
\hline Hindu & 23 & 9.2 \\
\hline Others & 2 & 0.8 \\
\hline Socioeconomic level & Frequency & Percent (\%) \\
\hline Low & 8 & 3.2 \\
\hline Middle & 226 & 90.4 \\
\hline High & 16 & 6.4 \\
\hline
\end{tabular}


Table 2. Food intake pattern of participants (here $\mathrm{F}$ for frequency and $\mathrm{P}$ for percent).

\begin{tabular}{|c|c|c|c|c|c|c|c|c|c|c|c|c|c|c|}
\hline \multirow[t]{2}{*}{$\begin{array}{l}\text { Name of } \\
\text { Different } \\
\text { food item }\end{array}$} & \multicolumn{2}{|c|}{ Never } & \multicolumn{2}{|c|}{ Rarely } & \multicolumn{2}{|c|}{$\begin{array}{l}\text { Less than } \\
\text { once week }\end{array}$} & \multicolumn{2}{|c|}{$\begin{array}{c}\text { Once } \\
\text { a week }\end{array}$} & \multicolumn{2}{|c|}{$\begin{array}{c}2 \text { or } 3 \text { times } \\
\text { a Week }\end{array}$} & \multicolumn{2}{|c|}{$\begin{array}{l}4 \text { or } 6 \text { times } \\
\text { a week }\end{array}$} & \multicolumn{2}{|c|}{ Everyday } \\
\hline & $\mathrm{F}$ & $\mathrm{P}$ & $\mathrm{F}$ & $\mathrm{P}$ & $\mathrm{F}$ & $\mathrm{P}$ & $\mathrm{F}$ & $\mathrm{P}$ & $\mathrm{F}$ & $\mathrm{P}$ & $\mathrm{F}$ & $\mathrm{P}$ & $\mathrm{F}$ & $\mathrm{P}$ \\
\hline Carbohydrate & 71 & $28.4 \%$ & 21 & $8.4 \%$ & 15 & $6 \%$ & 23 & $9.2 \%$ & 32 & $12.8 \%$ & 28 & $11.2 \%$ & 60 & $24 \%$ \\
\hline Meat & 11 & $4.4 \%$ & 20 & $8 \%$ & 10 & $4 \%$ & 28 & $11.2 \%$ & 31 & $12.4 \%$ & 49 & $19.6 \%$ & 101 & $40.4 \%$ \\
\hline $\begin{array}{l}\text { Junk food like burger, } \\
\text { pizza, French fries, fried food }\end{array}$ & 39 & $15.6 \%$ & 33 & 13. $2 \%$ & 21 & $8.4 \%$ & 38 & $15.2 \%$ & 22 & $8.8 \%$ & 44 & $17.6 \%$ & 53 & $21.2 \%$ \\
\hline Fruits, vegetables & 9 & $3.6 \%$ & 23 & $9.2 \%$ & 15 & $6 \%$ & 40 & $16 \%$ & 62 & $24.8 \%$ & 32 & $12.8 \%$ & 69 & $27.6 \%$ \\
\hline Small fish & 11 & $4.4 \%$ & 49 & $19.6 \%$ & 45 & $18 \%$ & 22 & $8.8 \%$ & 60 & $24 \%$ & 25 & $10 \%$ & 38 & $15.2 \%$ \\
\hline $\begin{array}{l}\text { Highly cooked Food, } \\
\text { red meat or processed food }\end{array}$ & 55 & $22 \%$ & 53 & $21.2 \%$ & 43 & $17.2 \%$ & 71 & $28.4 \%$ & 8 & $3.2 \%$ & 7 & $2.8 \%$ & 13 & $5.2 \%$ \\
\hline $\begin{array}{l}\text { Food like chips, } \\
\text { Soft drinks, popcorn }\end{array}$ & 3 & $1.2 \%$ & 48 & $19.2 \%$ & 24 & $9.6 \%$ & 36 & $14.4 \%$ & 30 & $12 \%$ & 20 & $8 \%$ & 89 & $35.6 \%$ \\
\hline
\end{tabular}

Table 3. Physical exercise patterns of the participants.

\begin{tabular}{|c|c|c|}
\hline Daily 1 hour physical activity & Frequency & Percent (\%) \\
\hline Yes & 139 & 55.6 \\
\hline No & 111 & 44.4 \\
\hline Doing exercise & Frequency & Percent (\%) \\
\hline Never & 79 & 31.6 \\
\hline Rarely & 93 & 37.2 \\
\hline Less than once a week & 19 & 7.6 \\
\hline Once a week & 19 & 7.6 \\
\hline 2 or 3 times a week & 21 & 8.4 \\
\hline 4 or 6 times a week & 10 & 4.0 \\
\hline Everyday & 9 & 3.6 \\
\hline Doing strenuous exercise & Frequency & Percent (\%) \\
\hline Never & 85 & 34.0 \\
\hline Rarely & 87 & 34.8 \\
\hline Less than once a week & 20 & 8.0 \\
\hline Once a week & 17 & 6.8 \\
\hline 2 or 3 times a week & 13 & 5.2 \\
\hline 4 or 6 times a week & 18 & 7.2 \\
\hline Everyday & 10 & 4.0 \\
\hline
\end{tabular}




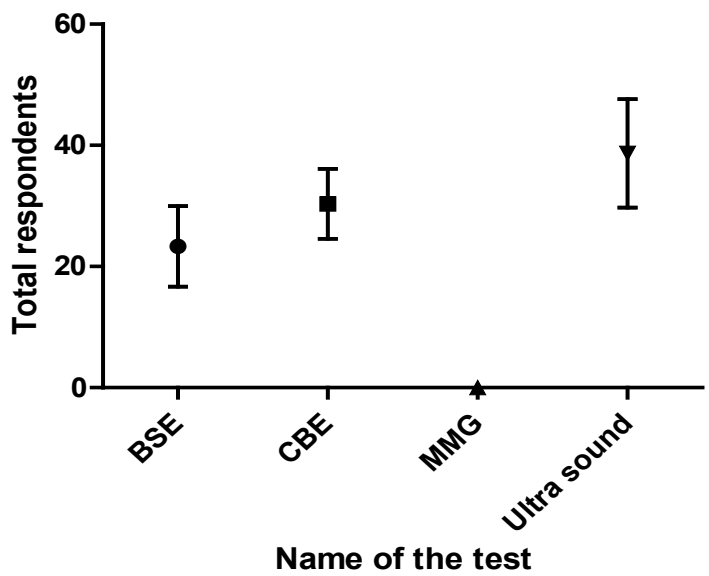

Figure 2. Participant's knowledge about different test methods. ( $P$ value $=0.0126$; Remarks-Significant).

Table 4. (a) Participants correct knowledge about risk factors and awareness of breast cancer; (b) Participants correct knowledge about early detection methods of breast cancer; (c) Practice of screening methods among participants.

(a)

\begin{tabular}{cccc}
\hline Risk factor & Undergraduate & Graduate & Total \\
\hline Family history of breast cancer & $12(4.8 \%)$ & $6(2.4 \%)$ & $18(7.2 \%)$ \\
Diet and diet related factors & $2(0.8 \%)$ & $5(2.0 \%)$ & $7(2.8 \%)$ \\
Hormones and reproductive factors & $3(1.2 \%)$ & $8(3.2 \%)$ & $11(4.4 \%)$ \\
Ionizing radiations & $\mathrm{Nil}$ & $\mathrm{Nil}$ & 00 \\
Benign breast diseases & $15(6.0 \%)$ & $21(8.4 \%)$ & $36(14.4 \%)$ \\
Increasing with age (age at menarche) & $5(2.0 \%)$ & $3(1.2 \%)$ & $8(3.2 \%)$ \\
Gender (being female) & $21(8.4 \%)$ & $13(5.2 \%)$ & $34(13.6 \%)$ \\
Lack of exercise & $9(3.6 \%)$ & $14(5.6 \%)$ & $23(9.2 \%)$ \\
\hline
\end{tabular}

(b)

\begin{tabular}{cccc}
\hline Test & Undergraduate & Graduate & Total \\
\hline BSE(Breast Self Examination) & $5(2.0 \%)$ & $18(7.2 \%)$ & $23(9.2 \%)$ \\
CBE(Clinical Breast Examination) & $19(7.6 \%)$ & $12(4.8 \%)$ & $31(12.4 \%)$ \\
Mammography (MMG) & Nil & Nil & Nil \\
Ultra sound for detection of breast tumor & $23(9.2 \%)$ & $16(6.4 \%)$ & $39(15.6 \%)$ \\
\hline
\end{tabular}

(c)

\begin{tabular}{cccc}
\hline Variable & Undergraduate & Graduate & Total \\
\hline Perform BSE at least once a month & $2(0.8 \%)$ & $11(4.4 \%)$ & $16(6.4 \%)$ \\
Performed CBE within last 1 year & $4(1.6 \%)$ & $1(0.4 \%)$ & $5(2.0 \%)$ \\
Had mammography in the past & Nil & Nil & Nil \\
Perform Ultra sound test procedure within last 1 year & $11(4.4 \%)$ & $13(5.2 \%)$ & $24(9.6 \%)$ \\
\hline
\end{tabular}


were also poor. Only $18 \%$ respondents performed at least one method for earlier breast cancer detection. Among them, 9.6\% participants performed Ultra sound test procedure within last 1 year (Figure 3 ).

The history of hereditary risk of cancer among the study participants was noticeable. In our study, $484.4 \%$ participants had not any family history of cancer where $7.6 \%$ did not know about it (Table 5). Only $6 \%$ girls had sister or mother who has cancer so that they were the most risk group of cancer. $7.2 \%$ girls also had at least two uncles, aunt, grandparents who bearded or bearing cancer.

Based on different risk factor, participants risk for breast or cervical cancer was also different. In this study, $0.8 \%$ participants drinking alcohol, $1.2 \%$ participants smoking cigarette, $15.6 \%$ participants wearing tight bra, 3.6\% participants have benign breast disease and no one have any mutation in BRCA1, BRCA2, PTEN, and TP53 genes (Table 6).

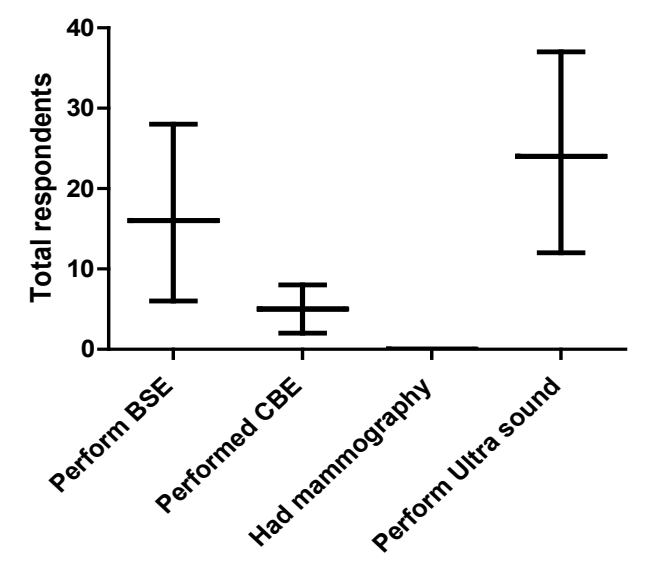

Practice of Screening Methods among participants

Figure 3. Practice of screening methods among respondents. (P value $=0.0290$; RemarksSignificant).

Table 5. History of the hereditary risk of participants for breast and cervical cancer.

\begin{tabular}{cc}
\hline Family member history of cancer & Frequency \\
Yes & $20(8 \%)$ \\
No & $211(84.4 \%)$ \\
Don't know & $19(7.6 \%)$ \\
\hline Sister or mother who have cancer & Frequency \\
\hline Yes & $15(6.0 \%)$ \\
No & $223(89.2 \%)$ \\
\hline Don't know & $12(4.8 \%)$ \\
\hline At least two uncles, aunt, grandparents who have cancer & Frequency \\
\hline Yes & $18(7.2 \%)$ \\
\hline No & $211(84.4 \%)$ \\
\hline
\end{tabular}


Table 6. Participants risk for cancer.

\begin{tabular}{ccc}
\hline Parameters & Frequency of "YES" & Frequency of "NO" \\
\hline Drinking alcohol & $2(0.8 \%)$ & $244(97.6 \%)$ \\
Smoking cigarette & $3(1.2 \%)$ & $243(97.2 \%)$ \\
Hormone replacement therapy & $2(0.8 \%)$ & $244(97.6 \%)$ \\
Wearing tight bra & $39(15.6 \%)$ & $207(82.8 \%)$ \\
Benign breast disease & $9(3.6 \%)$ & $237(94.4 \%)$ \\
Mutation in BRCA1, BRCA2, PTEN and TP53 genes & Nil & $246(100 \%)$
\end{tabular}

All the conscious participants of our study gathered information from different sources including TV (18\%), newspaper (31.6\%), women's magazine (6\%), radio (4\%), NHS website $(5.6 \%)$, other website $(4.4 \%)$, somewhere else can't remember (7.6\%), nurses (3.2\%), physicians (2.4\%), friends (6.4\%), relatives $(8.8 \%)$, and refused (2\%). These are illustrated in Figure 4 and it indicates the sorts of media that could be useful in disseminating the breast and cervical cancer key messages.

In our study it is clear that the attendance rate at breast or cervical cancer screening programs was significantly poor. Only $2.8 \%$ participants attended in screening programs while $95.6 \%$ never attended any program (Figure 5 ).

Among our study participants, 71.2\% participants never heard of Breast Self Exam (BSE) and 28.8\% participants ever heard about Breast Self Exam (Figure 6). The knowledge about the treatments of breast cancer is crucial to minimize the risk of it. According to our study, $40.4 \%$ girls have not any knowledge about breast cancer treatment. Most of them (24.8\%) recognize radiotherapy as breast cancer treatment. Others $15.2 \%$ recognize chemotherapy and $17.2 \%$ recognize surgery as breast cancer treatment. $41.40 \%$ participants said that they don't know about any treatments of breast cancer (Figure 7).

Among the participants, total 74 (29.6\%) girls thought that nipple retraction is the most common symptoms. Others participants also considered many others symptoms like breast pain 35 (14\%), breast skin change 32 (12.8), bloody nipple discharge $22(8.8 \%)$, painless lump 21 (12.4\%). 17.2\% girls said that they don't know about any symptoms (Figure 8).

According to this figure most of participants considered nipple retraction and few of them considered painless lump, breast pain as breast cancer symptoms. Among them, $18.14 \%$ participants don't have any knowledge about the symptoms. Among the participants, only 3\% know about only one early detection method of cervical cancer named "via examination", but 97\% know that there is no method yet has been developed for early detection of this cancer.

Among the participants of our study, probably half of the participants 127 (50.8\%) were unknown about cervical cancer treatments. About one fourth of the participants 58 (23.2\%) were known to chemotherapy (Figure 9).

Figure 10 represents the participants' knowledge about different warning signs of cervical cancer. In this survey, 66 (26.4\%) girls considered vaginal bleed- 


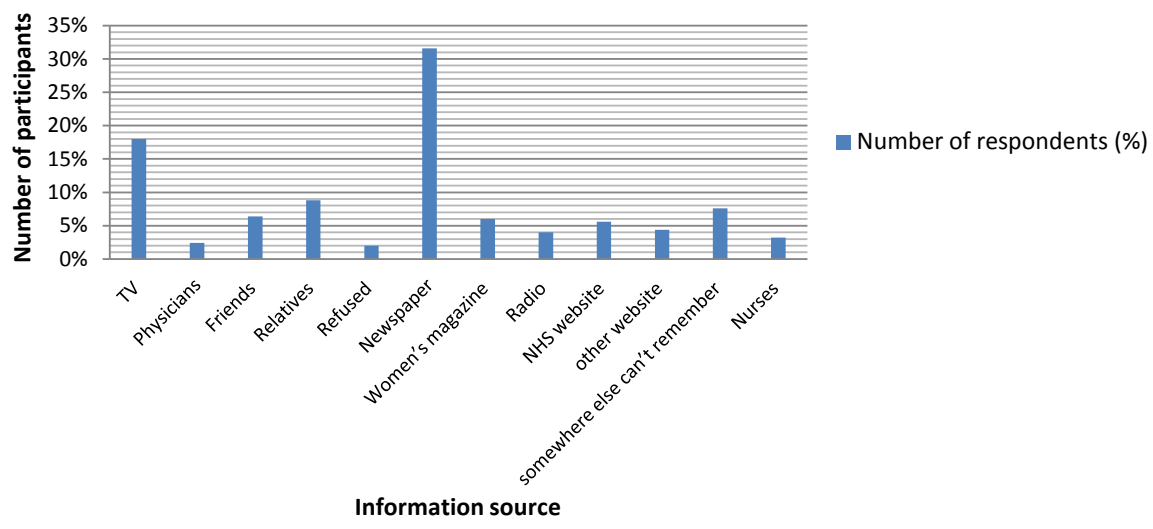

Figure 4. Source of information.

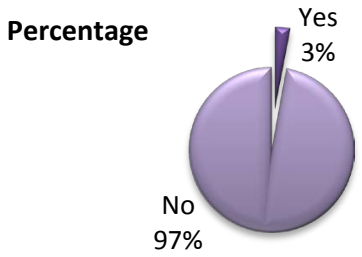

Figure 5. Graphic representation on attendance rate in breast or cervical cancer screening.

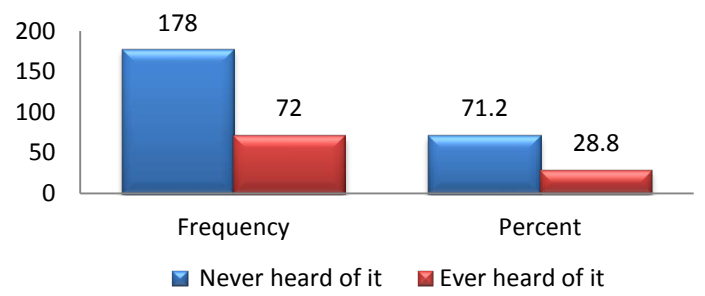

Figure 6. Graphic representation on knowledge about breast cancer screening practice.

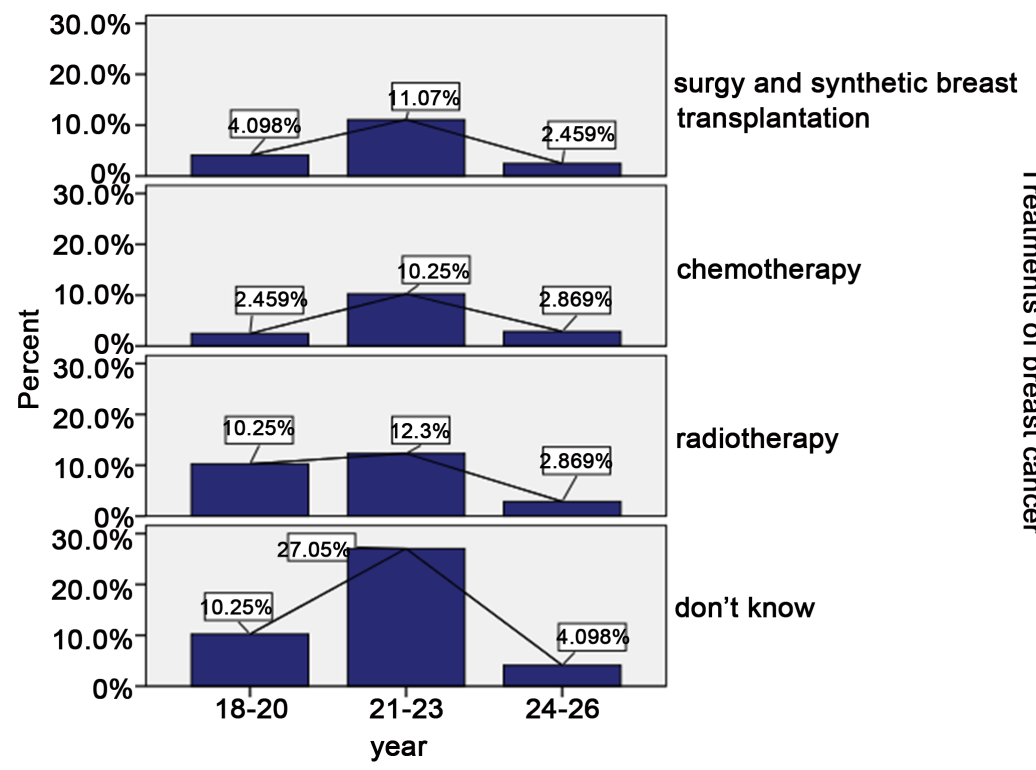

Figure 7. Graphic representation of Knowledge of participant about breast cancer treatment. 


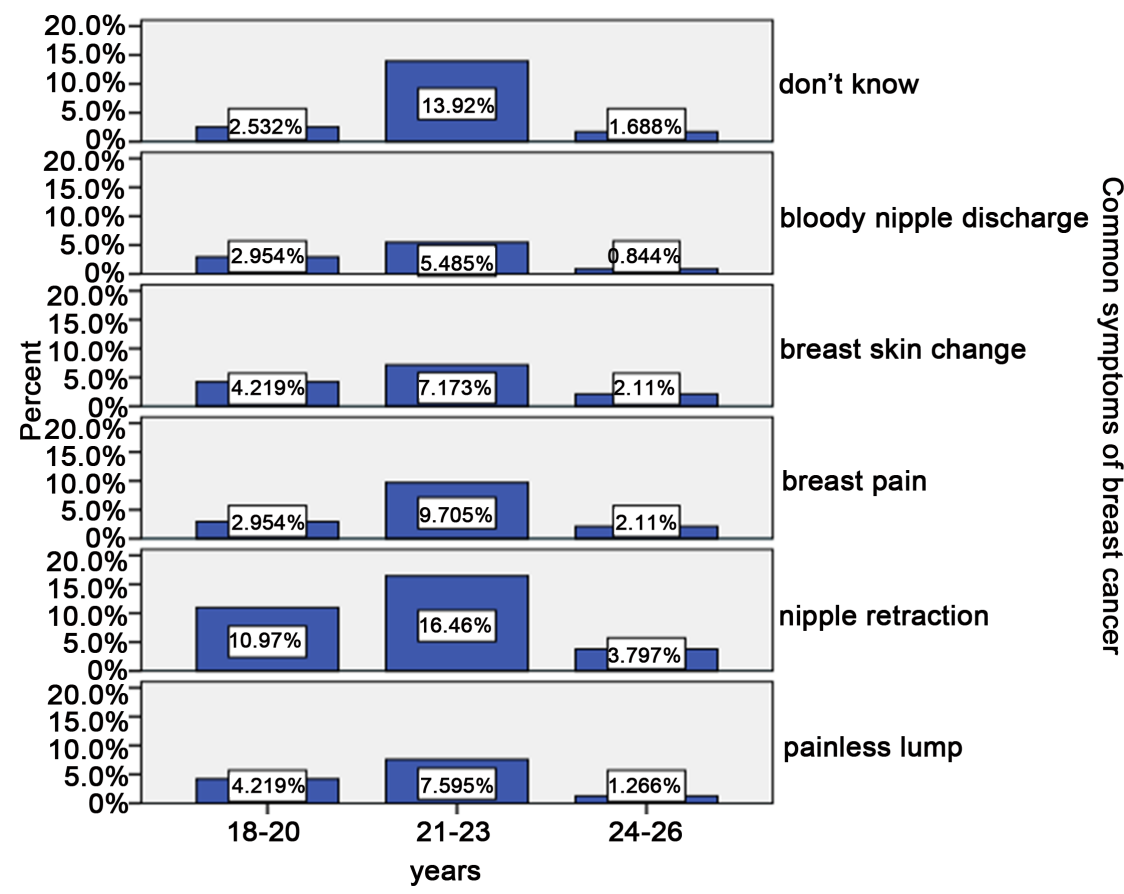

Figure 8. Graphic representation on awareness of participant about breast cancer symptoms.

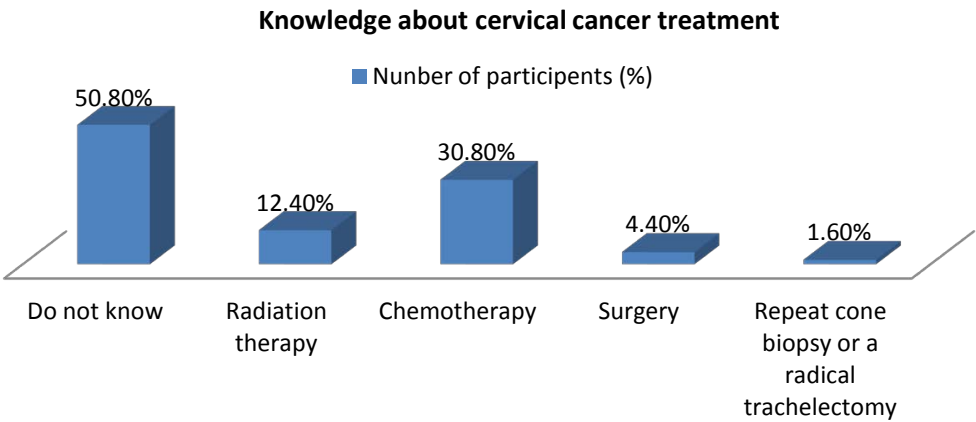

Figure 9. Graphic representation on knowledge about cervical cancer treatment.

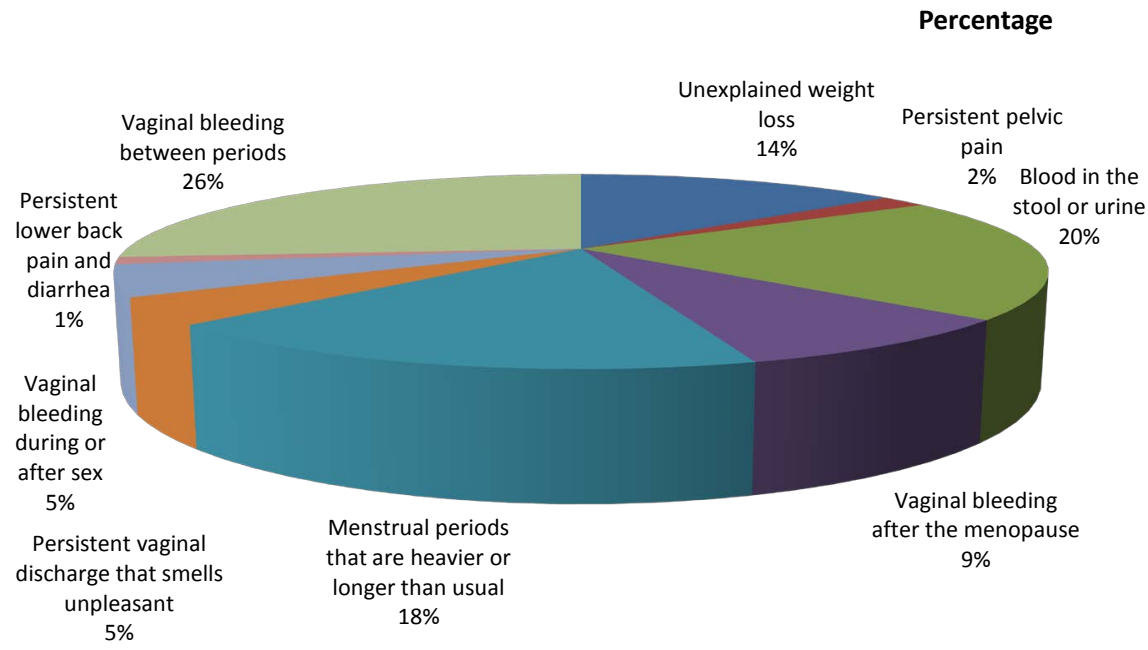

Figure 10. Graphic representation on knowledge of cervical cancer symptoms. 
ing between periods, 51 girls (20.4\%) considered Blood in the stool or urine, 44 girls (17.6\%) considered Menstrual periods that are heavier or longer than usual as warning signs. Others 35 (14\%) cited unexplained weight loss, $2 \%$ cited persistent pelvic pain, and $9 \%$ cited viginal bleeding after menopause.

Among the participants, most $(43,17.2 \%)$ participants thought that having a weekend immune system is a vital cervical cancer risk factor. About 7 (2.8\%) considered infection with HPV, 37 (14.8\%) considered smoking cigarettes, 29 (11.6\%) considered long term use of contraceptive pill, 11 (4.4\%) considered not going for regular smear or Pap test and only $2 \%$ considered having many children as cervical cancer risk factor (Figure 11).

In this study, it was clear that $68(27.2 \%)$ girls were not at all confident to identify a cervical cancer symptom. About $71(28.4 \%)$ participants cited that they are not very confident, 41 (16.4\%) cited that they are fairly confident, 29 $(11.6 \%)$ cited that they are very confident to identify a cervical cancer symptom (Figure 12).

\section{Discussion}

Socio-demographic profile showed different personal information of the participants. It revealed that most of them came from village and their knowledge about different treatment facilities was very poor. Others came from city or

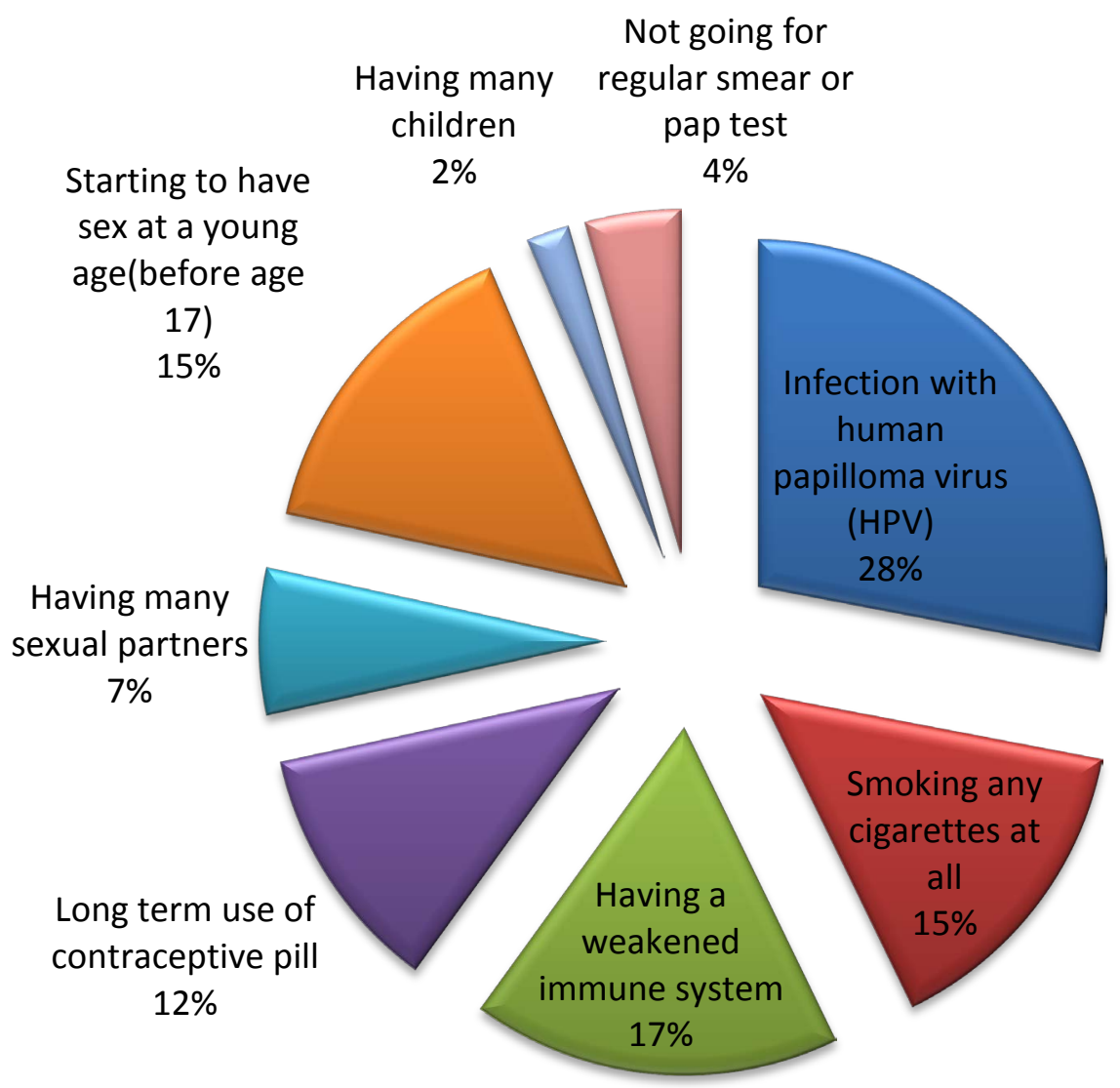

Figure 11. Graphic representation on knowledge of participants about cervical cancer risk factors. 


\section{Confidence level of participent about cervical cancer symptoms}

Participants confidence rate (\%)

$56.40 \%$

$28.40 \%$

$16.40 \%$

$11.60 \%$

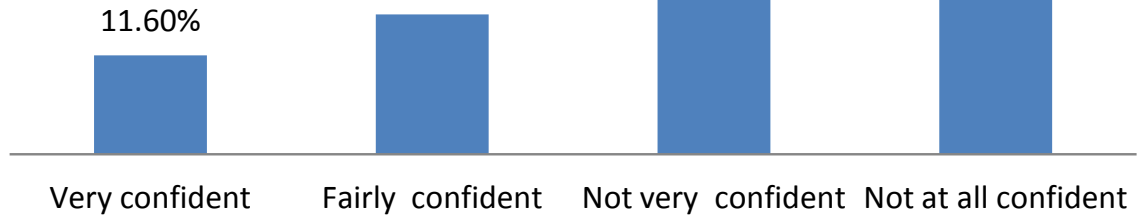

Figure 12. Graphic representation on confidence rate about cervical cancer symptoms.

semi-town, and their knowledge about breast and cervical cancer is not satisfactory. Most of the participants aged between (21 - 23) years and socioeconomic level was middle. In case of food intake patterns it was found that about $39.6 \%$ never eat grilled, barbecued, smoked food and they were not at risk of cancer but $34.8 \%$ who ate these food items rarely, were at lower risk. About 28.4\% participants who ate highly cooked food, red meat or processed food, $35.6 \%$ ate chips, soft drinks, popcorn every day; $40.4 \%$ ate meat every day, and $21.2 \%$ who ate different junk food like burger pizza, French fries, fried food etc. every day were higher risk of cancer because these food items indirectly responsible for cancer. Again the $6 \%$ girls whose sister or mother having cancer, were the most risk group of cancer. $7.2 \%$ girls who had at least two uncles, aunt, grandparents have been suffering from cancer were also a very higher risk of cancer. So it is essentials for them to do Pap test or mammogram or BSE regularly in order to prevent cancer.

The findings of this study revealed that participants habitual risk for cancer were not so high because only $0.8 \%$ participants drank alcohol, $1.2 \%$ participants smoked cigarette, $15.6 \%$ participants wear tight bra and $3.6 \%$ participants have benign breast disease. The results of this study implied that there was insufficient knowledge among the participants on the possible risk factors for breast cancer and cervical cancer. With regard to student's knowledge of BSE, results showed that the majority of the participants, $71.2 \%$ never heard of BSE. Subsequent findings showed that fewer and fewer students actually understand the procedures involved in BSE. Results showed that there is also poor knowledge of participants in other areas of breast or cervical cancer screening. Only $2.8 \%$ participants attended in screening programs. About $41.4 \%$ girls had not any knowledge about breast cancer treatment and probably half of the participants (50.8\%) were unknown about cervical cancer treatments. Some participants in (21 - 23) age group recognized radiotherapy $(12.3 \%)$ and chemotherapy $(10.25 \%)$ as reliable 
treatment process. In case of delayed treatment, a malignant breast tumor move towards advances stage and it is one of the main cause for increasing deaths in breast cancer [46]. Most of participants recognized nipple retraction and few of them recognized painless lump, breast pain etc. as main breast cancer symptoms. Patient delay in help-seeking refers to the period between an individual's first awareness of a sign or symptom of disease and initial medical consultation and that cause lower chances of survival. Patients with total delays of 3 - 6 months have considerably worse survival than those with delays of less than 3 month [47] [48]. Although surgery and chemo-radiotherapy can cure 80\% - 95\% of women with early stage cancer, the recurrent and metastatic disease remains a major cause of cancer death [49]. With regard to student's knowledge of different warning signs and symptoms, results showed that the majority of the participants $(29.6 \%)$ recognize nipple retraction as the common symptoms of breast cancer; $17.2 \%$ participants recognize having a weekend immune system as cervical cancer risk factor; $26.4 \%$ girls recognize vaginal bleeding between periods as warning signs of cervical cancer.

In order to reduce the morbidity and mortality breast self-examination (BSE), clinical breast examination and mammography are recommended for detecting breast cancer at an early stage. Pap test or Smear test is used to detect cervical cancer. Because of poor understanding of cervical and breast cancer screening procedures, lack of female screeners or convenient clinic times, fear of embarrassment and many more reasons women's are not generally attend the screening programs. Different source like TV, newspaper, women's magazine, NHS website etc are very essential source for information about two leading cancer. This study aims to develop ideas about these sources and increasing their attendance in screening programs. In order to raise awareness, awareness generation programs like IEC (Information, Education, and Communication) activities are essential. We should promote more open discussion of cancer symptom to minimize the embarrassment. Some special and specific campaign should be done to aware students about early detection tests like BSE. HPV vaccination represents a great hope in the fight against cervical cancer, so women should be encouraged for HPV vaccination.

\section{Conclusion}

Control of Breast and cervical cancer in a low-income country such as Bangladesh is a challenging endeavor because both cancers are major life-threatening public health problem. Long-term increases in the incidence of the diseases are being observed in both industrialized and developing world. The goal of reducing the suffering and death from breast and cervical cancer depends completely on proper awareness, knowledge and attitude. This study was conducted to determine knowledge, attitude, awareness about breast and cervical cancer among the female students of Mawlana Bhashani Science and Technology University. The main purpose of the study was to find out prevalence of breast and cervical cancer development. It can be concluded that the participants have very poor 
knowledge about treatments, symptoms and risk factors towards breast and cervical cancer. This problem should not be ignored and the student's attitude towards breast and cervical cancer needs to be developed. In developing countries, where screening services are sporadic because of unpredictable funding and poor infrastructure, only awareness, knowledge and attitude can make a great hope to fight against breast cancer and cervical cancer. Much work is needed to raise awareness about signs, symptoms, risk factors, screening methods and treatments of breast cancer and cervical cancer, particularly those of early stage of disease highlighted in the key messages. Information especially needs to be targeted at women from low social grades to high social grades.

\section{References}

[1] Sultana, N., Begum, H.A., et al. (2011) Perception of Genital Cancer among Women Attending the OPD of Tertiary Care Hospital in Old Part of Dhaka City. Journal of Dhaka National Medical College \& Hospital, 17, 45-57.

[2] Hussain, A.S. and Sullivan, R. (2013) Cancer Control in Bangladesh. Japanese Journal of Clinical Oncology, 43, 1159-1169. https://doi.org/10.1093/jjco/hyt140

[3] Ferlay, J., Hery, C., Autier, P. and Sankaranarayanan, R. (2010) Global Burden of Breast Cancer. In: Li, C., Ed., Breast Cancer Epidemiology, Springer, New York, 1-19. https://doi.org/10.1007/978-1-4419-0685-4_1

[4] Tavassoli, F.A., et al. (2003) World Health Organization Classification of Tumors: Pathology and Genetics of Tumors of the Breast and Female Genital Organs. Vol. 5, IARC Press, Lyon, 14-15.

[5] Siegel, R., Naishadham, D. and Jemal, A. (2013) Cancer Statistics, 2013. CA: $A$ Cancer Journal for Clinicians, 63, 11-30. https://doi.org/10.3322/caac.21166

[6] Weiss, J.R., Moysich, K.B. and Swede, H. (2005) Epidemiology of Male Breast Cancer. Cancer Epidemiology, Biomarkers \& Prevention, 14, 20-26.

[7] Deb, S., Jene, N., kConFab investigators and Fox, S.B. (2012) Genotypic and Phenotypic Analysis of Familial Male Breast Cancer Shows under Representation of the HER2 and Basal Subtypes in BRCA-Associated Carcinomas. BMC Cancer, 12, 510 537. https://doi.org/10.1186/1471-2407-12-510

[8] Davis, N.M., Melissa Sokolosky, M., et al. (2015) Deregulation of the EGFR/PI3K/ PTEN/Akt/mTORC1 Pathway in Breast Cancer: Possibilities for Therapeutic Intervention. Oncotarget, 5, 4603-4650. https://doi.org/10.18632/oncotarget.2209

[9] (2014) American Cancer Society. Detailed Guide: Breast Cancer. http://www.cancer.org/Cancer/BreastCancer/DetailedGuide/index

[10] Angelis, D.R., Tavilla, A., et al. (2016) Breast Cancer Survivors in the United States: Geographic Variability and time Trends, 2005-2015. Cancer, 115, 1954-1966. https://doi.org/10.1002/cncr.24217

[11] Rosedale, M. and Fu, M.R. (2010) Confronting the Unexpected: Temporal, Situational, and Attributive Dimensions of Distressing Symptom Experience for Breast Cancer Survivors. Oncology Nursing Forum, 37, 28-33. https://doi.org/10.1188/10.onf.e28-e33

[12] Bodai, B.I. and Tuso, F. (2015) Breast Cancer Survivorship: A Comprehensive Review of Long-Term Medical Issues and Lifestyle Recommendations. The Permanente Journal, 19, 48-79. https://doi.org/10.7812/TPP/14-241

[13] Howell, A., Anderson, A.S., et al. (2014) Risk Determination and Prevention of 
Breast Cancer. Breast Cancer Research, 16, 446-457. https://doi.org/10.1186/s13058-014-0446-2

[14] Li, J., Lindstro, L.S., et al. (2014) 2q36.3 Is Associated with Prognosis for Oestrogen Receptor-Negative Breast Cancer Patients Treated with Chemotherapy. Nature Communications, 5, Article No. 4051.

[15] Morandi, A., Martin, L., et al. (2013) GDNF-RET Signaling in ER-Positive Breast Cancers Is a Key Determinant of Response and Resistance to Aromatase Inhibitors. Cancer Research, 73, 3783-3795. https://doi.org/10.1158/0008-5472.CAN-12-4265

[16] Pettersson, A., Graff, R.E., et al. (2014) Mammographic Density Phenotypes and Risk of Breast Cancer: A Meta-analysis. Journal of the National Cancer Institute, 106, 112-123. https://doi.org/10.1093/jnci/dju078

[17] Maguire, S.L., Leonidou, A., et al. (2015) SF3B1 Mutations Constitute a Novel Therapeutic Target in Breast Cancer. Journal of Pathology, 235, 571-580. https://doi.org/10.1002/path.4483

[18] Sawyer, E., Roylance, R., et al. (2014) Genetic Predisposition to in Situ and Invasive Lobular Carcinoma of the Breast. PLoS Genetics, 10, e1004285. https://doi.org/10.1371/journal.pgen.1004285

[19] Mousavi, S.M., Gouya, M.M., et al. (2009) Cancer Incidence and Mortality in Iran. Annals of Oncology, 20, 556-563. https://doi.org/10.1093/annonc/mdn642

[20] Sarfo, A.L., Awuah-Peasah, D., Acheampong, E. and Asamoah, F. (2012) Knowledge, Attitude, and Practice of Self-Breast Examination among Female University Students at Presbyterian University College, Ghana. American Journal of Research Communication, 1, 395-396.

[21] Faronbi, J.O. and Abolade, J. (2012) Breast Self-Examination Practices among Female Secondary School Teachers in a Rural Community in Oyo State, Nigeria. Open Journal of Nursing, 2, 111-115. http://dx.doi.org/10.4236/ojn.2012.22017

[22] ARC (2012) GLOBOCAN 2012: Estimated Cancer Incidence, Mortality and Prevalence Worldwide in 2012. http://globocan.iarc.fr/Pages/fact_sheets_cancer.aspx

[23] De Vito, C., Angeloni, C., et al. (2014) A Large Cross-Sectional Survey Investigating the Knowledge of Cervical Cancer Risk Etiology and the Predictors of the Adherence to Cervical Cancer Screening Related to Mass Media Campaign. Bio-Med Research International, 2014, Article ID: 304602.

[24] Lopez, A.J.G. and Lopez, J.A. (2014) Multistep Model of Cervical Cancer: Participation of miRNAs and Coding Genes. International Journal of Molecular Sciences, 15, 15700-15733. https://doi.org/10.3390/ijms150915700

[25] Parkin, D.M., Bray, F., Ferlay, J. and Pisani, P. (2001) Estimating the World Cancer Burden: Globocan 2000. International Journal of Cancer, 94, 153-156.

https://doi.org/10.1002/ijc.1440

[26] Chakrabarti, O. and Krishna, S. (2003) Molecular Interactions of "High Risk" Human Papillomaviruses E6 and E7 Oncoproteins: Implications for Tumour Progression. Journal of Biosciences, 28, 337-348. https://doi.org/10.1007/bf02970152

[27] Maio, D. and Liao, J.B. (2006) Human Papillomaviruses and Cervical Cancer. Advances in Virus Research, 66, 125-159.

[28] Huang, R.L., Chang, C.C., et al. (2012) Methylomic Analysis Identifies Frequent DNA Methylation of Zinc Finger Protein 582 (ZNF582) in Cervical Neoplasms. PLoS ONE, 7, e41060. https://doi.org/10.1371/journal.pone.0041060

[29] Forouzanfar, M.H., Foreman, K.J., et al. (2011) Breast and Cervical Cancer in 187 Countries between 1980 and 2010: A Systematic Analysis. The Lancet, 378, 14611484. https://doi.org/10.1016/S0140-6736(11)61351-2 
[30] Walboomers, J.M., Jacobs, M.V., et al. (1999) Human Papillomavirus Is a Necessary Cause of Invasive Cervical Cancer Worldwide. The Journal of Pathology, 189, 1219.

https://doi.org/10.1002/(SICI)1096-9896(199909)189:1<12::AID-PATH431>3.0.CO; $\underline{2-\mathrm{F}}$

[31] Miller, J.W., Hanson, V., Johnson, G.D., Royalty, J.E. and Richardson, L.C. (2014) From Cancer Screening to Treatment: Service Delivery and Referral in the National Breast and Cervical Cancer Early Detection Program. Cancer, 120, 2549-2556. https://doi.org/10.1002/cncr.28823

[32] Tabatabai, M.A., Keumo, J.J.K., et al. (2014) Disparities in Cervical Cancer Mortality Rates as Determined by the Longitudinal Hyperbolastic Mixed-Effects Type II Model. PLoS ONE, 9, e107242. https://doi.org/10.1371/journal.pone.0107242

[33] Mwaka, A.D., Wabinga, H.R. and Mayanja-Kizza, H. (2014) Mind the Gaps: A Qualitative Study of Perceptions of Healthcare Professionals on Challenges and Proposed Remedies for Cervical Cancer Help-Seeking in Post Conflict Northern Uganda. BMC Family Practice, 14, 193.

[34] Mackay, H.J., Wenzel, L. and Mileshkin, L. (2015) Nonsurgical Management of Cervical Cancer: Locally Advanced, Recurrent, and Metastatic Disease, Survivorship, and Beyond. American Society of Clinical Oncology-Educational Book, 299309. https://doi.org/10.14694/EdBook_AM.2015.35.e299

[35] Min, K.J., Lee, Y.J., et al. (2015) The Korean Guideline for Cervical Cancer Screening. Journal of Gynecologic Oncology, 26, 232-239. https://doi.org/10.3802/jgo.2015.26.3.232

[36] Bourgioti, C., Chatoupis, K., et al. (2016) Current Imaging Strategies for the Evaluation of Uterine Cervical Cancer. World Journal of Radiology, 8, 342-354. https://doi.org/10.4329/wjr.v8.i4.342

[37] American Cancer Society (2015) Cancer Facts \& Figures 2015. American Cancer Society, Atlanta.

[38] Institute for Health Metrics and Evaluation (2011) The Challenge Ahead: Progress and Setbacks in Breast and Cervical Cancer. IHME, Seattle, WA.

[39] Ekechi, C., Olaitan, A., et al. (2014) Knowledge of Cervical Cancer and Attendance at Cervical Cancer Screening: A Survey of Black Women in London. BMC Public Health, 14, 1096. https://doi.org/10.1186/1471-2458-14-1096

[40] Lemlem, B.S., Sinishaw, W., et al. (2013) Assessment of Knowledge of Breast Cancer and Screening Methods among Nurses in University Hospitals in Addis Ababa, Ethiopia, 2011. ISRN Oncology, 2013, Article ID: 470981.

https://doi.org/10.1155/2013/470981

[41] Fotedar, V., Seam, K.R., et al. (2013) Knowledge of Risk Factors \& Early Detection Methods and Practices towards Breast Cancer among Nurses in Indira Gandhi Medical College, Shimla, Himachal Pradesh, India. Asian Pacific Journal of Cancer Prevention, 14, 117-120. https://doi.org/10.7314/APJCP.2013.14.1.117

[42] Ralston, D.J., Taylor, M.V., et al. (2006) Knowledge of Cervical Cancer Risk Factors among Chinese Immigrants in Seattle. Journal of Tropical Medicine, 28, 41-57.

[43] Uddin, K.F.A., Khan, J.Z., Islam, J. and Mahmud, A.M. (2013) Cancer Care Scenario in Bangladesh. South Asian Journal of Cancer, 2, 102-104.

https://doi.org/10.4103/2278-330X.110510

[44] Madanat, H. and Merrill, M.R. (2002) Breast Cancer Risk-factor and Screening Awareness among Women Nurses and Teachers in Amman, Jordan. Cancer Nursing, 25, 276-282. https://doi.org/10.1097/00002820-200208000-00003 
[45] Lewitowicz, P., Horecka-Lewitowicz, A. and Adamczyk-Gruszka, O. (2013) Knowledge of Cervical Cancer Risk Factors among Students at the Jan Kochanowski University in Kielce. Studia Medyczne, 29, 255-259. https://doi.org/10.5114/ms.2013.38582

[46] Facione, N.C. (1993) Delay versus Help Seeking for Breast Cancer Symptoms: A Critical Review of the Literature on Patient and Provider Delay. Social Science \& Medicine, 36, 1521-1534.

[47] Hussain, A.S. and Sullivan, R. (2013) Cancer Control in Bangladesh. Japanese Journal of Clinical Oncology, 43, 1159-1169.

[48] Ferlay, J., Steliarova-Foucher, E., Lortet-Tieulent, J., Rosso, S., Coebergh, J.W.W., Comber, H., Forman, D. and Bray, F. (2013) Cancer Incidence and Mortality Patterns in Europe: Estimates for 40 Countries in 2012. European Journal of Cancer, 49, 1374-1403. http://dx.doi.org/10.1016/j.ejca.2012.12.027

[49] Peralta-Zaragoza, O., Bermúdez-Morales, H.V., et al. (2012) Targeted Treatments for Cervical Cancer: A Review. OncoTargets and Therapy, 5, 315-328.

\section{Submit or recommend next manuscript to SCIRP and we will provide best} service for you:

Accepting pre-submission inquiries through Email, Facebook, LinkedIn, Twitter, etc. A wide selection of journals (inclusive of 9 subjects, more than 200 journals)

Providing 24-hour high-quality service

User-friendly online submission system

Fair and swift peer-review system

Efficient typesetting and proofreading procedure

Display of the result of downloads and visits, as well as the number of cited articles

Maximum dissemination of your research work

Submit your manuscript at: http://papersubmission.scirp.org/

Or contact abcr@scirp.org 